\title{
Adsorption Capacity of Expansion Graphite for Xylenol Orange
}

\author{
Xiuyan Pang ${ }^{1^{*}}$, Chunyan Yang ${ }^{1,2}$, Shuxia Ren ${ }^{1}$ \\ ${ }^{1}$ College of Chemistry and Environmental Science, Hebei University, Baoding, China \\ ${ }^{2}$ Baoding Tianwei Wind Power Blade Co. Ltd, Baoding, China \\ Email: "pxy833@163.com
}

Received 2013

\begin{abstract}
Expansion graphite (EG) processing of an expanded volume of $400 \mathrm{~mL} / \mathrm{g}$ was prepared with 50 mesh crude graphite after chemical oxidation intercalation of potassium permanganate and vitriol, and its adsorption kinetics and thermodynamics characteristics for xylenol orange (XO) was investigated. In thermodynamic study, adsorption isotherm and free energy change $\left(\Delta \mathrm{G}^{\circ}\right)$ were detected and calculated, respectively. Influence of ionic strength on adsorbance was investigated. Kinetic studies were carried out with a series of XO concentration under different temperatures, and the data were simulated with pseudo first-order and second-order kinetic model, respectively. Results illustrate: adsorption of EG for XO is a spontaneous process, and adsorption isotherm is type II; equilibrium adsorbance increases with the increase of ionic strength. Kinetic studies show that the kinetic data can be delineated by pseudo second-order kinetic model. Initial adsorption rate increases with the increase of temperature. Adsorption activation energy is less than 20 $\mathrm{kJ} / \mathrm{mol}$; physical adsorption is the major mode of the overall adsorption process.
\end{abstract}

Keywords: Expansion Graphite; Xylenol Orange; Adsorption Kinetics; Adsorption Thermodynamics; Physical Adsorption

\section{Introduction}

Expansion graphite (EG) is a kind of porous material prepared through chemical oxidation or electric chemical oxidation [1,2]. EG had attracted attention of scientists and engineers as an adsorbent of organic substance, such as heavy oil [3-7]. As for the adsorption study for dyes, Wang pressed the worm-like particles into a low-density plate of $0.1 \mathrm{~g} / \mathrm{cm}^{3}$ [8], then the plate was used to treat dye waste-water from woolen mill, and the optimum applying condition was tested. Wang investigated the influence factors in adsorption process [9], and concluded that the adsorption capacity was affected by EG expansion volume and dosage, primary concentration of dyes, contact time, $\mathrm{pH}$ and temperature. But they neglected the influence of $\mathrm{pH}$ both on absorbency and adsorption capacity, and improper $\mathrm{pH}$ was used. At the same time, high EG dosage along with dyes low initial concentration caused adsorption isotherms of the tested dyes were all type I. Pang investigated the adsorption kinetic characteristics of Acid Red 3B on EG [10], and the kinetic data could be delineated by pseudo second-order kinetic model.

Xylenol orange (XO) is one kind of dye with triphenylmethane structure, it is widely used as chemical indi- cator and dye, and then causes plenty of wastewater. In its decoloration with coal powder [11] as adsorbent, the influence of adsorbent dosage, XO primary concentration, contact time and $\mathrm{pH}$ was investigated. Under the condition of $\mathrm{pH} 4$, dosage of coal powder $8.0 \mathrm{~g} / \mathrm{L}$ and $\mathrm{XO}$ initial concentration of $7.6 \mathrm{mg} / \mathrm{L}$, A decoloration rate of $85 \%$ was gained after a $2.0 \mathrm{~h}$ decoloration treatment. With chitosan microsphere as adsorbent [12], the opti-

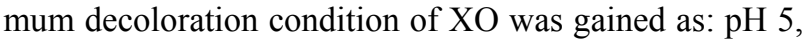
$2.0 \mathrm{~h}$, dosage of chitosan microsphere with a diameter of $74 \mu \mathrm{m} 0.3 \mathrm{~g} / \mathrm{L}$ and XO initial concentration of $32 \mathrm{mg} / \mathrm{L}$. As an adsorbent, EG adsorption capacity for $\mathrm{XO}$ has not been reported. The aim of the study is to investigate the adsorption characteristics of EG-XO system in water solution, and discuss the effect of ionic strength, concentration, temperature, and do further evaluation of applicability of common isotherm model (i.e., Langmuir and Freundlich) and pseudo-second-order rate model.

\section{Experimental}

\subsection{Adsorbent}

EG was prepared according to [13]. Its pore distribution was detected with Micromeritics Instrument Corporation 
TriStar II $3020 \mathrm{~V} 1.02$, and pore structure parameters were calculated with BET method and shown in Table 1.

\subsection{Adsorbate}

$\mathrm{XO}$ molecular structure and molecular weight is shown in Table 2. Its simulated wastewater was prepared by dissolving the dye in distilled deionized water at various concentrations. Color measurements were made with T6 New Century UV spectrophotometry (Puxi Tongyong Instrument Limited Company of Beijing) operating in the visible range on absorbance mode. Absorbance values were recorded at the wavelength for maximum absorbance $\left(\lambda_{\max }\right)$, and $\mathrm{XO}$ solution was initially calibrated for concentration in terms of absorbance units.

\subsection{Methods}

Static adsorption of XO: $0.200 \mathrm{~g}$ of EG is mixed in conical glass flasks with $100 \mathrm{~mL}$ solution at the desired $\mathrm{XO}$ concentration and ionic strength. Ionic strength is adjusted with $\mathrm{NaCl}$ or $\mathrm{Na}_{2} \mathrm{SO}_{4}$ solution. Adsorption adsorbance was calculated according to Equation (1).

$$
q=V\left(C_{0}-C_{t}\right) / M
$$

$q$ : Accumulative adsorbance of $\mathrm{XO}$ on $\mathrm{EG}$ at the moment of $\mathrm{t}, \mathrm{mg} / \mathrm{g} ; C_{t}$ : Concentration of $\mathrm{XO}$ in solution at the moment of $\mathrm{t}, \mathrm{mg} / \mathrm{L} ; M$ : mass of $\mathrm{EG}$

Adsorption kinetics experiments of XO: Adsorption kinetics experiments were carried out using a HZS-D shaking water bath with a shaking speed of $100 \mathrm{rpm} / \mathrm{min}$. A series of desired $\mathrm{XO}$ concentration and a fixed volume of $100 \mathrm{~mL}$ were placed in vessels, where they were brought into contact with $0.200 \mathrm{~g} \mathrm{EG}$ at $15^{\circ} \mathrm{C}, 25^{\circ} \mathrm{C}$ and $35^{\circ} \mathrm{C}$, respectively. Amount of XO captured by EG at different time is determined according to Equation (1).

Table 1. Structural parameter of $\mathbf{E G}^{\mathrm{a}}$.

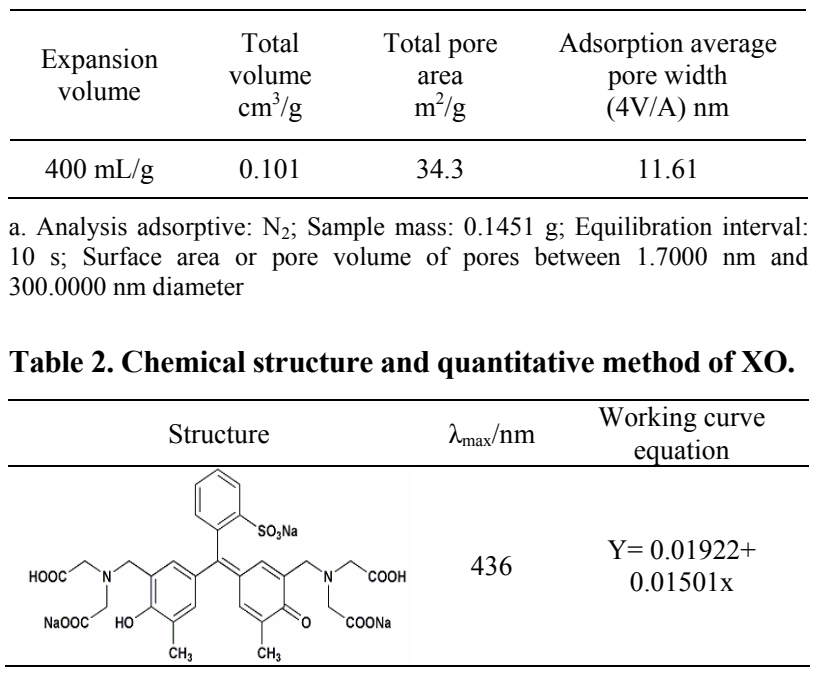

\section{Results}

\subsection{Adsorption Thermodynamics}

Investigation of adsorption isotherm and thermodynamic parameters: Static adsorption capacity of XO was detected as Figure 1. It is a typical II type isotherm, multilayer adsorption occurs on EG surface. In the condition of monolayer adsorption, the thermodynamic data were treated with Langmuir and Freundlich isotherm Equations (2) and (3), respectively. As shown in Table 3, Langmuir isotherm gives better results than Freundlich isotherm, and the monolayer saturation adsorbance of $\mathrm{XO}$ is $18.15 \mathrm{mg} / \mathrm{g}$. But the total adsorbance increase with the increase of $\mathrm{XO}$ initial and equilibrium concentration due to its multilayer adsorption.

Langmuir equation: $1 / \mathrm{q}_{\mathrm{e}}=1 / \mathrm{q}_{0}+\mathrm{A} /\left(\mathrm{q}_{0} \times \mathrm{C}_{\mathrm{e}}\right)$

Freundlich equation: $\ln _{\mathrm{e}}=\ln \mathrm{K}_{\mathrm{F}}+(1 / \mathrm{n}) \ln \mathrm{C}_{\mathrm{e}}$

$q_{0}$ : Saturation adsorption amount of XO in forming complete monolayer coverage on EG pore surface, $\mathrm{mg} / \mathrm{g} ; A$ : Equilibrium concentration of $\mathrm{XO}$ corresponding to half saturation adsorbance, $\mathrm{mg} / \mathrm{mL} ; K_{F}$ : Freundlich equation constant; $1 / n$ : Adsorption intensity for Freundlich equation

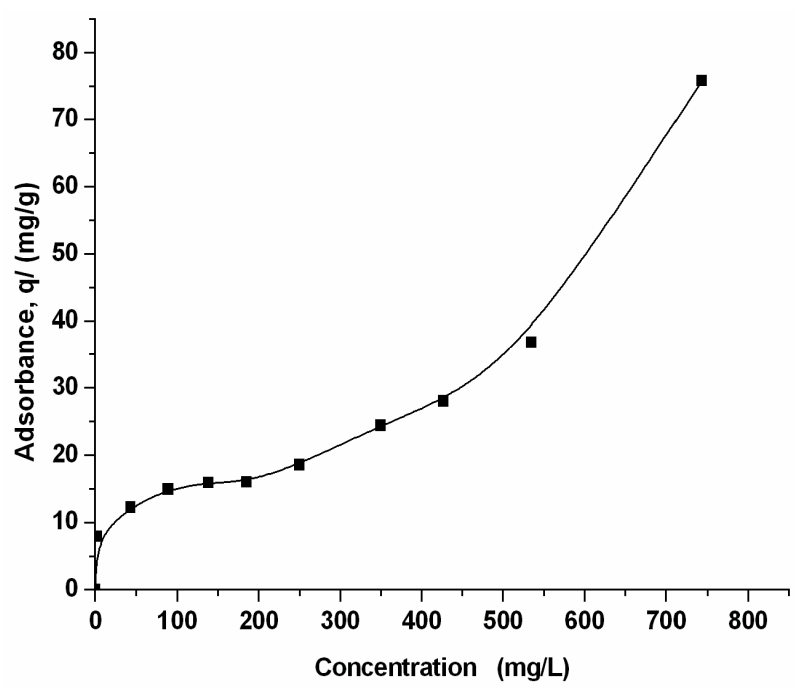

Figure 1. Adsorption isotherm of $\mathrm{XO}$ at $15^{\circ} \mathrm{C}$.

Table 3. Langmuir and Freundlich isotherm constants of $\mathrm{XO}$ at $15^{\circ} \mathrm{C}$.

\begin{tabular}{ccccccc}
\hline & Langmuir & \multicolumn{4}{c}{ Freundlich } \\
\hline $\mathrm{q}_{\mathrm{o}} \mathrm{mg} / \mathrm{g}$ & $\mathrm{A}$ & $\mathrm{r}$ & $\mathrm{K}_{\mathrm{F}}$ & $1 / \mathrm{n}$ & $\mathrm{r}$ \\
18.15 & 0.0301 & 0.999 & 4.1915 & 0.3197 & 0.84 \\
\hline
\end{tabular}


At the same time, adsorption free energy change $\left(\triangle G^{\circ}\right)$ is calculated according to Equation (4), the value is $8.388 \mathrm{~kJ} / \mathrm{mol}$, negative $\triangle G^{\circ}$ indicates that adsorption of $\mathrm{XO}$ on $\mathrm{EG}$ is spontaneous.

$$
\triangle G^{\circ}=-R T \ln b
$$

$b$ : Langmuire equation constant; $\triangle G^{\circ}$ : The free energy change in the adsorption, $\mathrm{kJ} / \mathrm{mol}$

Influence of ion strength on adsorption capacity: $\mathrm{NaCl}$ and $\mathrm{Na}_{2} \mathrm{SO}_{4}$ were used respectively to adjust solution ionic strength in the range of 0 to $0.6 \mathrm{~mol} / \mathrm{L}$ with $\mathrm{MO}$ concentration keeping $200 \mathrm{mg} / \mathrm{L}$ and $500 \mathrm{mg} / \mathrm{L}$, respectively. Influence of ionic strength on adsorbance (shown in Figure 2) indicates that presence of salt ions can improve the adsorption capacity of EG for XO, and it might be caused by the increase of hydrophobic attraction of $\mathrm{XO}$ due to the "salting-out" effect. Under the same mass concentration, the influence of $\mathrm{Na}_{2} \mathrm{SO}_{4}$ is higher than that of $\mathrm{NaCl}$.

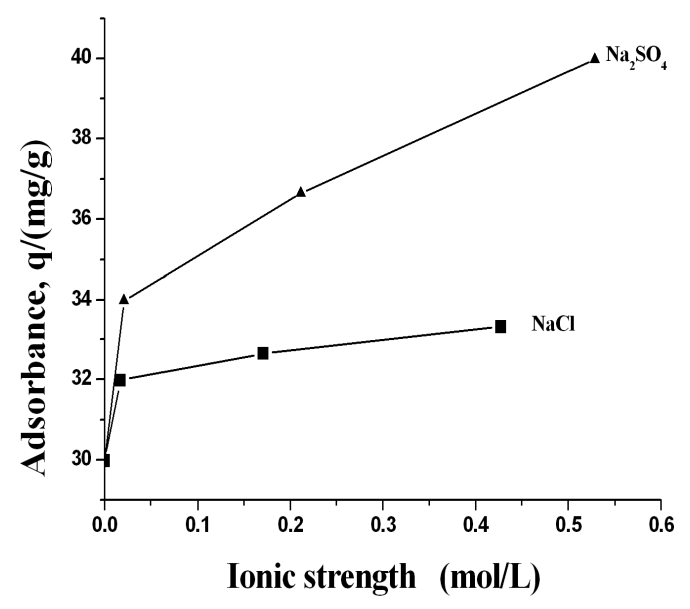

(a) MO concentration $200 \mathrm{mg} \cdot \mathrm{L}^{-1}$

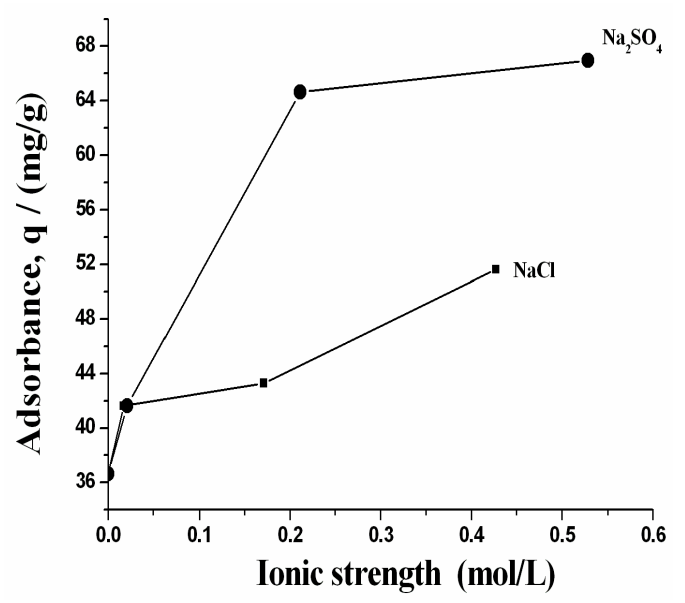

(b) MO concentration $500 \mathrm{mg} \cdot \mathrm{L}^{-1}$

Figure 2. Influence of ionic strength on adsorption capacity of EG for XO.

\subsection{Adsorption Kinetics}

Equilibrium time: Influences of $\mathrm{XO}$ concentration and temperature on adsorption equilibrium time were detected and shown in Figure 3. Results suggest that adsorbance is the function of XO concentration, temperature and adsorption time. In the beginning, adsorption rate increases with the increase of temperature, but temperature has no obvious influence on adsorption equilibrium time. In kinetic experiment, all adsorption could reach equilibrium within $24.0 \mathrm{~h}$.

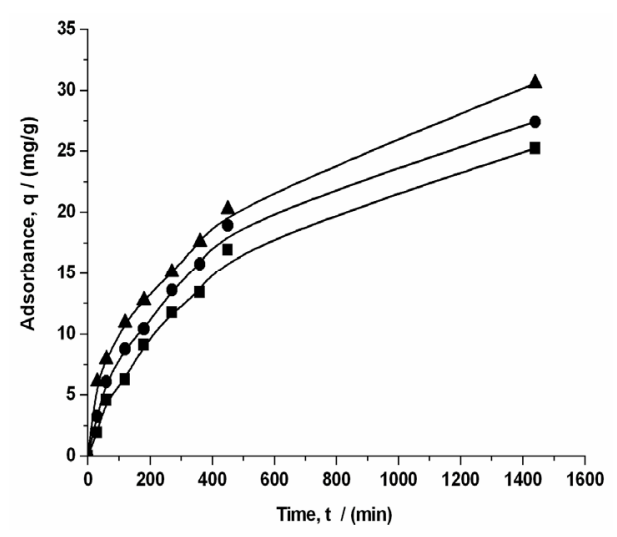

(a) XO initial concentration $100 \mathrm{mg} / \mathrm{L}$

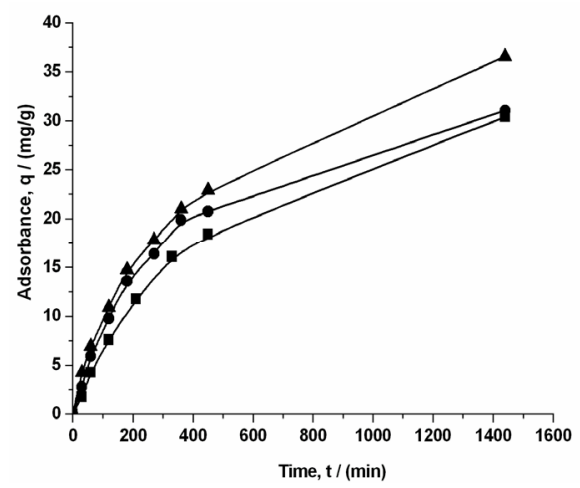

(b) XO initial concentration $200 \mathrm{mg} / \mathrm{L}$

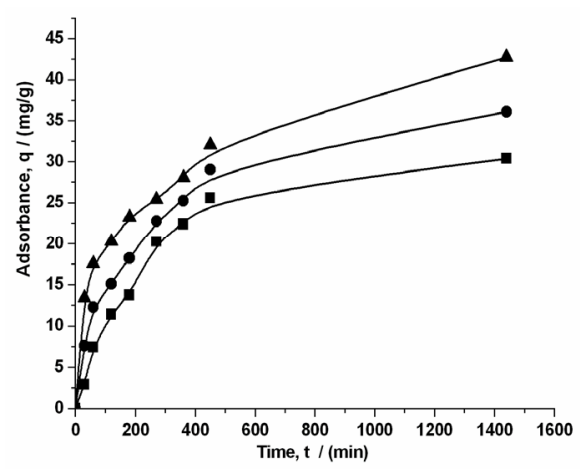

(c) XO initial concentration $300 \mathrm{mg} / \mathrm{L}$

Figure 3. Influence of initial concentration and temperature on adsorption kinetics 
Adsorption kinetic models: Both pseudo first- and second-order adsorption models were used to describe the adsorption kinetics data according to Equation (5) and (6) $[14,15]$.

First-order model: $\quad \ln \left(\mathrm{q}_{\mathrm{e}}-\mathrm{q}\right)=\ln \mathrm{q}_{\mathrm{e}}-\mathrm{kt}$

Second-order model: $\quad \mathrm{t} / \mathrm{q}=1 /\left(\mathrm{k} \mathrm{q}_{\mathrm{e}}{ }^{2}\right)+\mathrm{t} / \mathrm{q}_{\mathrm{e}}$

$k$ : Adsorption rate constant $\left(\mathrm{min}^{-1}\right.$ for first-order adsorption, $\mathrm{g} /(\mathrm{mg} \cdot \mathrm{min})$ for second-order adsorption); $t$ : Adsorption time, $\min$

Since $q$ reached $q_{\mathrm{e}}$ at equilibrium, $q$ values smaller than $0.9 q_{\mathrm{e}}$ were used for analysis. Plots of $\ln \left(q_{\mathrm{e}}-q\right)$ versus $t$ and $t / q$ versus $t$ were used to test the first- and second-order models, and the fitting results were given in
Table 4. Not only the line curve fit, but also $q_{\mathrm{e}, \mathrm{cal}}$, second-order model agrees more well with experimental data than first-order model. Second-order model is more suitable to describe XO kinetics data. Similar results were observed in the adsorption of EG for Acid Red 3B [10].

Based on the second-order model, initial adsorption rate and half-adsorption time were estimated according to Equations (7) and (8). As shown in Table 5, initial adsorption rate $u$ increases with the increase of initial XO concentration and temperature. But there is no obvious relativity between half-adsorption time $t_{1 / 2}$ and temperature, XO concentration, respectively. The results are consistent with experiment data.

Table 4. Adsorption kinetics model comparison of EG for XO.

\begin{tabular}{|c|c|c|c|c|c|c|c|c|}
\hline \multirow[b]{2}{*}{$\begin{array}{c}\mathrm{C}_{0} \\
\mathrm{mg} / \mathrm{L}\end{array}$} & \multirow[b]{2}{*}{$\begin{array}{l}\mathrm{T} \\
{ }^{\circ} \mathrm{C}\end{array}$} & \multirow[b]{2}{*}{$\begin{array}{l}\mathrm{q}_{\mathrm{e}, \mathrm{exp}} \\
\mathrm{mg} / \mathrm{g}\end{array}$} & \multicolumn{3}{|c|}{ First-order } & \multicolumn{3}{|c|}{ Second-order } \\
\hline & & & $\begin{array}{l}\mathrm{q}_{\mathrm{e}, \mathrm{cal}} \\
\mathrm{mg} / \mathrm{g}\end{array}$ & $\begin{array}{c}\mathrm{k} \\
\min ^{-1}\end{array}$ & $\mathrm{r}$ & $\begin{array}{c}\mathrm{q}_{\mathrm{e}, \mathrm{cal}} \\
\mathrm{mg} / \mathrm{g}\end{array}$ & $\begin{array}{l}\mathrm{k} / 10^{-5} \\
\mathrm{~g} /(\mathrm{mg} \\
\cdot \min ) \\
\end{array}$ & $\mathrm{r}$ \\
\hline \multirow{3}{*}{100} & 15 & 25.24 & 21.88 & 0.0028 & -0.985 & 24.77 & 6.9 & 0.996 \\
\hline & 25 & 27.40 & 22.95 & 0.123 & -0.977 & 26.38 & 8.7 & 0.993 \\
\hline & 35 & 30.57 & 30.89 & 0.12 & -0.979 & 30.33 & 10.0 & 0.984 \\
\hline \multirow{3}{*}{200} & 15 & 30.40 & 28.31 & 0.118 & -0.979 & 31.39 & 4.5 & 0.999 \\
\hline & 25 & 31.07 & 28.77 & 0.118 & -0.970 & 32.69 & 6.0 & 0.999 \\
\hline & 35 & 36.56 & 35.74 & 0.138 & -0.983 & 35.02 & 7.2 & 0.999 \\
\hline \multirow{3}{*}{300} & 15 & 30.40 & 32.63 & 0.211 & -0.986 & 30.43 & 10.6 & 0.995 \\
\hline & 25 & 36.06 & 36.95 & 0.147 & -0.987 & 36.23 & 14.0 & 0.997 \\
\hline & 35 & 42.73 & 33.19 & 0.152 & -0.943 & 43.34 & 14.0 & 0.992 \\
\hline
\end{tabular}

Table 5. The second-order model parameters of EG for XO.

\begin{tabular}{|c|c|c|c|c|c|}
\hline $\begin{array}{c}\mathrm{C}_{0} \\
\mathrm{mg} / \mathrm{L}\end{array}$ & $\begin{array}{c}\mathrm{T} \\
{ }^{\circ} \mathrm{C}\end{array}$ & $\begin{array}{c}\mathrm{u} \\
\mathrm{mg} /(\mathrm{g} \cdot \min )\end{array}$ & $\begin{array}{l}\mathrm{t}_{1 / 2} \\
\mathrm{~min}\end{array}$ & $\begin{array}{c}\mathrm{Ea} \\
\mathrm{kJ} / \mathrm{mol}\end{array}$ & $\mathrm{r}$ \\
\hline \multirow{3}{*}{100} & 15 & 0.0743 & 572.96 & \multirow{3}{*}{14.28} & \multirow{3}{*}{-0.994} \\
\hline & 25 & 0.0976 & 416.67 & & \\
\hline & 35 & 0.1219 & 321.43 & & \\
\hline \multirow{3}{*}{200} & 15 & 0.0783 & 719.41 & \multirow{3}{*}{17.50} & \multirow{3}{*}{-0.999} \\
\hline & 25 & 0.1081 & 445.97 & & \\
\hline & 35 & 0.1219 & 454.59 & & \\
\hline \multirow{3}{*}{300} & 15 & 0.1218 & 307.77 & \multirow{3}{*}{9.059} & \multirow{3}{*}{-0.991} \\
\hline & 25 & 0.2231 & 201.07 & & \\
\hline & 35 & 0.2932 & 171.39 & & \\
\hline
\end{tabular}




$$
\begin{gathered}
\mathrm{u}=\mathrm{kq}_{\mathrm{e}}{ }^{2} \\
\mathrm{t}_{1 / 2}=1 /\left(\mathrm{k} \mathrm{q}_{\mathrm{e}}\right)
\end{gathered}
$$

$u$ : Initial adsorption rate, $(\mathrm{mg} / \mathrm{g} \cdot \mathrm{min}) ; \quad t_{1 / 2}$ : Half-adsorption time (min)

To judge the sorption belongs to physical adsorption or chemical adsorption, the second-order rate constants are used to estimate activation energy of XO adsorption on EG using Arrhenius Equation (9). Plots of $\ln k$ versus $1 / T$ is used to evaluate $E$ a, and it is found less than 20.0 $\mathrm{kJ} / \mathrm{mol}$ (as shown in Table 5). So, the adsorption between $\mathrm{EG}$ and $\mathrm{XO}$ is mainly physical adsorption.

$$
\mathrm{Lnk}=\mathrm{LnA}-\mathrm{Ea} /(\mathrm{RT})
$$

$A$ : The re-exponential factor, $\mathrm{g} /(\mathrm{mg} \cdot \mathrm{min}) ; E a$ : The adsorption activation energy, $\mathrm{kJ} / \mathrm{mol}$

\section{Conclusion}

This study has provided an insight into the adsorption characteristics of EG for XO.

Thermodynamics study illustrates: adsorption of XO on EG is a spontaneous process, and the adsorption isotherm is type II. Adsorption process is affected by multifactor, not only the initial concentration, temperature, but also the ionic strength of solution. High XO initial concentration and ionic strength are propitious to adsorbance.

Kinetic study illustrates: adsorption kinetics can be well described by the pseudo second-order kinetic model. Initial adsorption rate increases with the increase of temperature. Active energy of adsorption is less than 20 $\mathrm{kJ} / \mathrm{mol}$; and the sorption between EG and XO belongs to physical adsorption.

\section{REFERENCES}

[1] M. L. Xue, Y. L. Yu, Z. H. Ren and J. S. Zhang, "Improvement in Electrochemical Synthesis of Expanded Graphite," Fine Chemicals, Vol. 19, No. 10, 2002, pp. 567-570.

[2] J. H. Li, Q. Y. Liu, M. Li and Z. R. Liu, "Preparation of Low-sulphur Expandable Graphite," Fine Chemicals, Vol. 20, No. 6, 2003, pp. 341-342.

[3] M. Toyoda, K. Moriya, J. I. Aizawa, H. Konno and M. Inagaki, "Sorption and Recovery of Heavy Oils by Using
Exfoliated Graphite Part I: Maximum Sorption Capacity," Desalination, Vol. 128, No. 3, 2000, pp. 205-211. doi:10.1016/S0011-9164(00)00034-5

[4] M. Inagaki, H. Konno, M. Toyoda, K. Moriya and T. Kihara, "Sorption and Recovery of Heavy Oils by Using Exfoliated Graphite Part II: Recovery of Heavy Oil and Recycling of Exfoliated Graphite," Desalination, Vol. 128, No. 3, 2000, pp. 213-218. doi:10.1016/S0011-9164(00)00035-7

[5] M. Inagaki, K. Shibata, S. Setou, M. Toyoda and J. I. Aizawa, "Sorption and Recovery of Heavy Oils by Using Exfoliated Graphite Part III: Trials for Practical Applications," Desalination, Vol. 128, No. 3, 2000, pp. 219-222. doi.:10.1016/S0011-9164(00)00036-9

[6] M. Toyoda, Y. Nishi, N. Iwashita and M. Inagaki, "Sorption and Recovery of Heavy Oils Using Exfoliated Graphite Part IV: Discussion of High Oil Sorption of Exfoliated Graphite," Desalination, Vol. 151, No. 3, 2003, pp. 139-144. doi:10.1016/S0011-9164(02)00992-X

[7] M. Inagaki, T. Nagata, T. Suwa and M. Toyoda, "Sorption Kinetics of Various Oils onto Exfoliated Graphite," New Carbon Materials, Vol. 21, No. 2, 2006, pp. 97-102.

[8] L. N. Wang, X. Chen, Y. P. Zheng, F. Y. Kang, J. F. Chen and W. C. Shen, "Application of Expansion Graphite on the Treatment of Woolen Mill Waste-water," Guide Journal of Chinese Non-metal Mine Industry, No. 5, 2004, pp. 59-62.

[9] L. N. Yang, "Study on the Adsorption of Expansion Graphite for Dyes," Master of Science, Thesis, Hebei Normal University, Shijiazhuang, 2004.

[10] X. Y. Pang and F. Gong, "Study on the Adsorption Kinetics of Acid Red 3B on Expanded Graphite," E-Journal of Chemistry, Vol. 5, No. 4, 2008, pp. 802-809. doi: $10.1155 / 2008 / 786025$

[11] Q. K. Hu and W. Jie, "Study on Removal of Xylenol Orange from Water by Fly-ash," Shanghai Chemical Industry, Vol. 31, No. 9, 2006, pp. 5-7.

[12] S. Wang, M. Y. Zheng, G. H. Ye and J. C. Guo, "Preparation of Chitosan Microspheres for Adsorptive Removal of Xylenol Orange," Environmental Pollution \& Control, Vol. 30, No. 12, 2008, pp. 43-46.

[13] L. J. Xu, "Study on the Adsorption and Competitive Adsorption Capacities of Expanded Graphite for Environmental Pollutants," Master of Science, Hebei University, Baoding, 2011.

[14] Z. Aksu, "Biosorption of Reactive Dyes by Dried Activated Sludge: Equilibrium and Kinetic Modeling," Biochemical Engineering, Vol. 7, No. 1, 2001, pp. 79-84. doi:10.1016/S1369-703X(00)00098-X

[15] Z. J. Wu, H. Joo and K. Lee, "Kinetics and Thermodynamics of the Organic Dye Adsorption on the Mesoporous Hybrid Xerogel," Chemical Engineering Journal, Vol. 112, No. 1-3, 2005, pp. 227-236. doi:10.1016/j.cej.2005.07.011 